\title{
Influence of the Rate and Degree of Deformation on the Texture, Structure and Mechanical Properties of Steel
}

\author{
V. V. Usov, ${ }^{1}$ N. M. Shkatulyak, ${ }^{1}$ A. A. Bryukhanov, ${ }^{1}$ and D. Fasmann ${ }^{2}$ \\ ${ }^{1}$ South Ukrainian National Pedagogical University Named after K. D. Ushynsky, 26 Staroportofrankovskaya Street, \\ Odessa 65020, Ukraine \\ ${ }^{2}$ Institute of Materials Science, Leibniz University of Hannover, 30823 Garbsen, Hannover, Germany \\ Correspondence should be addressed to V. V. Usov; valentin_usov50@mail.ru
}

Received 28 October 2013; Revised 17 January 2014; Accepted 31 January 2014; Published 24 March 2014

Academic Editor: Michael E. Kassner

Copyright (C) 2014 V. V. Usov et al. This is an open access article distributed under the Creative Commons Attribution License, which permits unrestricted use, distribution, and reproduction in any medium, provided the original work is properly cited.

\begin{abstract}
The tests of uniaxial tensile by 10,20 , and $30 \%$ at strain rates of $0.1,1,60,120$, and $300 \mathrm{~mm} / \mathrm{min}$ in rolling direction and transverse direction of recrystallized cold-rolled low-carbon steel sheets were carried out. The effect of rate and degree of deformation on the texture, structure, and mechanical properties were studied. The texture transformations and the growth of the anisotropy of mechanical properties with increasing strain rate up to $120 \mathrm{~mm} / \mathrm{min}$ are explained by the effect of crystallographic intragranular slip and twinning of deformation mechanism. The further increase of deformation rate leads to texture scattering and decreasing of properties anisotropy, which are bound to the difficulty of intragranular sliding and activation of grain boundary sliding.
\end{abstract}

\section{Introduction}

The deformation of polycrystalline metal forms the preferential crystal orientation or texture. Type of texture depends on many factors, namely, circuit deformation, crystal structure of the metal, temperature, strain rate, and all. The deformation ratio and temperature are generally studied in connection with their effects on the deformation resistance of the metal during processing pressure $[1,2]$. The nature of the texture that formed at different strain rates and temperatures of deformation during the mechanical tests remains often unclear. However, the study of the crystallographic texture of deformed polycrystals allows determining the mechanisms operating during plastic deformation of the metal and determining the nature of change of its physical-mechanical properties [3]. In [4] studied the effect of strain rate during the uniaxial tensile tests on the formation of the texture, but influence of the deformation degree in this case was not investigated.

The aim of the present work is to study the texture, microstructure, mechanisms of plastic deformation, and the change of the mechanical properties under different rates of deformation and its degree of uniaxial tensile of low-carbon steel sheets.

\section{Materials and Methods}

The low-carbon cold-rolled steel sheets $0.95 \mathrm{~mm}$ in thickness after recrystallization annealing were studied. The chemical composition of steel was $0.06 \% \mathrm{C}, 0.35 \% \mathrm{Mn}, 0.40 \% \mathrm{Si}$, and $\sim 0.025 \% \mathrm{~S}$ and $\mathrm{P}$, the masses in \%. Specimens for mechanical tests of initial length of the working part $50 \mathrm{~mm}$ and a width of $12.5 \mathrm{~mm}$ were cut from the sheets in the rolling direction (RD) and transverse direction (TD). Mechanical testing was carried out by uniaxial tension at room temperature by means of tensile machine 250N5A WN 143331 with force sensor ID $0 \mathrm{WN} 80550620 \mathrm{kN}$. The strain rates of $0.1 \mathrm{~mm} / \mathrm{min}$, $1 \mathrm{~mm} / \mathrm{min}, 60 \mathrm{~mm} / \mathrm{min}, 120 \mathrm{~mm} / \mathrm{min}$, and $300 \mathrm{~mm} / \mathrm{min}$ were applied.

Crystallographic texture was studied after uniaxial tensile tests of 10,20 , and $30 \%$ by means of electron backscatter diffraction (Method EBSD) [5] from the RD. After deformation, surface of deformed sample (perpendicular to tensile 
axis) was prepared for EBSD study by conventional mechanical grinding and polishing, followed by final vibratory polishing. Data on the microstructure and texture obtained electron microscope LEO $1455 \mathrm{VP}$ at accelerating voltage of $20 \mathrm{kV}$. The step size was $0.17 \mu \mathrm{m}$. To describe the texture were using inverse pole figures (IPF) of rolling direction (RD), normal direction (ND), and transverse direction (TD).

\section{Results and Discussions}

Experimental IPF of steel after tensile at different strain rates on different strain degrees are represented in Figures 1-3. The corresponding microstructures are shown in Figure 4 . The initial average grain size measured in two mutually perpendicular directions $(\mathrm{TD} \times \mathrm{ND})$ was $14 \times 7 \mu \mathrm{m}$ (Figure 4(a)). The interpretation of the texture data was carried out on the basis of following (conceptions) regularities. The activation of the known crystallographic mechanisms of slip and twinning along certain crystallographic planes and directions develops textures of a particular type. Activation of grain boundary sliding is not associated with the formation of crystallographic texture and leads to weakening and scattering texture that already exists in the material [6].

On the IPF (ND) of the initial specimen (Figure 1(a)) the absolute maximum of pole density of $\sim 10^{0}$ displaces on $\sim 10$ from the pole $\langle 111\rangle$ along the diagonal $\langle 111\rangle-\langle 100\rangle$ stereographic triangle. There is wide scatter of the pole density. In addition there are two other pole density maxima at $\sim 7$ near the $\langle 113\rangle$ (with a scatter up to $\langle 321\rangle$ ) and $\langle 320\rangle$.

On the IPF (RD) a maximum of $\sim 14$ displaces from the pole $\langle 110\rangle$ to $\langle 320\rangle$. On the IPF (TD) of the initial specimen two intense $\sim 14$ maximum pole densities are observed. One coincides with the $\langle 111\rangle$ direction, and the second is shifted from the $\langle 111\rangle$ to $\sim 100$ along the diagonal $\langle 111\rangle-\langle 100\rangle$ stereographic triangle. This indicates the presence of a partial axial texture in the texture plane deformation. The origin of one of them is related to the rotation of orientations of the type $\{h k l\}\langle 110\rangle$ in a constrained deformation around the RD [7]. The second axial orientation is caused by rotation around the $\langle 111\rangle$ [7]. Thus, texture of original sheet is characterized by superposition round $\{113\}(110)$ and $\{111\}\langle 110\rangle$ recrystallization texture of mild steel [8].

When the tensile strain is $10-30 \%$ at a strain rate of $0.1 \mathrm{~mm} / \mathrm{min}$, the grains in the sample rotate so that crystallographic $\langle 110\rangle$ axes coincide with the RD. The limited axial texture with axis almost coinciding with the $\langle 110\rangle$ direction is formed in the samples. The pole density of $\langle 110\rangle$ is $\sim 14$ in the IPF (RD) (Figures 1(b)-3(b)). When takes rotation around the indicated axes, the normal direction coincides with different probability with normals to crystallographic planes $\{111\},\{113\},\{112\},\{335\},\{221\}$, and $\{355\}$, as seen from IPF (ND). The pole density of 8 observed on the IPF (ND) near $\sim\langle 113\rangle$ may be caused by twinning in the conjugate plane $\{112\}$ of the main tensile texture component $\langle 110\rangle$ or by compression along the ND during deformation by tensile along the $\mathrm{RD}$ in the test [7]. Area of high pole density of value $\sim 10$ near pole $\langle 335\rangle$ scattered up to $\langle 111\rangle$ observed on the IPF (TD). Activation of the crystallographic slip on the systems $\{110\}\langle 111\rangle$ may result in the formation of such textures [7]. Thus, the axial texture with axis $\langle 110\rangle$ parallel to the RD begins to form in the sheet after tensile on $10 \%$ at strain rate of $0.1 \mathrm{~mm} / \mathrm{min}$.

The intense maximum $\sim 12$ near pole $\{111\}$ on IPF (TD) is observed (Figure 2(b)) if tensile degree is $20 \%$ at a strain rate of $0.1 \mathrm{~mm} / \mathrm{min}$. This indicates the formation of the planar texture of the type $\{112\}\langle 111\rangle$.

The abovementioned planar texture weakens since the intensity maximum at about $\{111\}$ pole on IPF (TD) reduces to 8 and the area of high pole density becomes wider after uniaxial tensile strain by $30 \%$ at a rate of $0.1 \mathrm{~mm} / \mathrm{min}$ (Figure 3(b)).

Tensile strain by $10 \%$ at a strain rate of $1 \mathrm{~mm} / \mathrm{min}$ leads to improvement of axial texture $\langle 110\rangle$ along RD with a maximum density of about 14 (Figure $1(\mathrm{c})$ ) due to the action of the abovementioned crystallographic deformation mechanisms. During the tensile of the sample along the RD the compression in the ND takes place. Thus the maxima of pole density value of $\sim 11$ and $\sim 7$ about $\{553\}$ and $\{533\}$, respectively, on IPF (ND) are formed. The maxima of this type $\{h h l\}$ and $\{h l l\}$ with high values of $h$ and $l(h>1)$ are formed by compression, if the primary and cross slip are carried out [7]. The limited axial texture with the axis of $\sim\langle 533\rangle$ parallel to the TD is formed in this case, as seen in the OPF (TD), where the maximal pole density $\sim 12$ is observed to be about $\{533\}$.

Thus, a limited axial texture between $\approx\{335\}\langle 110\rangle$ and $\{355\}\langle 110\rangle$ with the axis $\langle 110\rangle$ parallel ND is formed in sheet after tensile strain by $10 \%$ with strain rate of $1 \mathrm{~mm} / \mathrm{min}$.

Similar texture is formed at the tensile strain of $20 \%$ at the strain rate of $1 \mathrm{~mm} / \mathrm{min}$ (Figure $3(\mathrm{c})$ ).

A planar deformation texture near to the $\{112\}\langle 111\rangle$ is formed in the sample at a tensile strain of $30 \%$ at a strain rate of $1 \mathrm{~mm} / \mathrm{min}$ (Figure 3(c)).

For the sample deformed with the tensile strain by $10 \%$ at the strain rate of $60 \mathrm{~mm} / \mathrm{min}$ the displacement of the axis $\langle 110\rangle$ to $\langle 320\rangle$ (pole density is $\sim 10$ ) on the IPF (RD) and also the scattering texture on IPF (ND) are observed (Figure $1(\mathrm{~d})$ ). The peak of high intensity (with pole density $\sim 14$ ) is formed in pole $\langle 111\rangle$ on the IPF (TD) at the same time.

This testifies to the rotation of the crystals around the TD under tensile. Thus, the limited axial texture between $\approx\{112\}\langle 110\rangle$ and $\{123\}\langle 320\rangle$ with the axis $\langle 111\rangle$ parallel to the TD is formed when tensile strain rate increases to $60 \mathrm{~mm} / \mathrm{min}$.

When tensile strain is $20 \%$ at a strain rate of $60 \mathrm{~mm} / \mathrm{min}$ (Figure 2(d)), the texture formed is similar to the texture that was formed by means of tensile strain of $10 \%$ at strain rate of $0.1 \mathrm{~mm} / \mathrm{min}$ (Figure 1(b)). This testifies to similar deformation mechanisms that operate at appropriate deformation modes.

Tensile strain in the $\mathrm{RD}$ by $30 \%$ at strain rate of $60 \mathrm{~mm} / \mathrm{min}$ (Figure 3(d)) promotes the formation of texture with the axes $\langle 210\rangle,\langle 320\rangle$, and $\langle 331\rangle$ parallel to the tensile direction. The similar orientations may be caused by twinning on the twinning plane $(\overline{1} \overline{1} 2)$. The twinning dislocation is $(1 / 6) a$ [111] for crystals adjacent to the [001]. Slip system, 

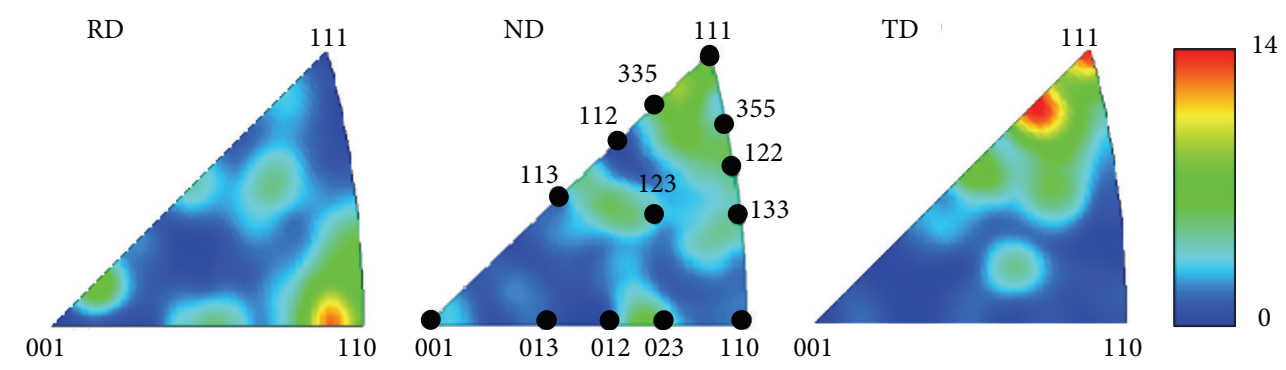

(a)
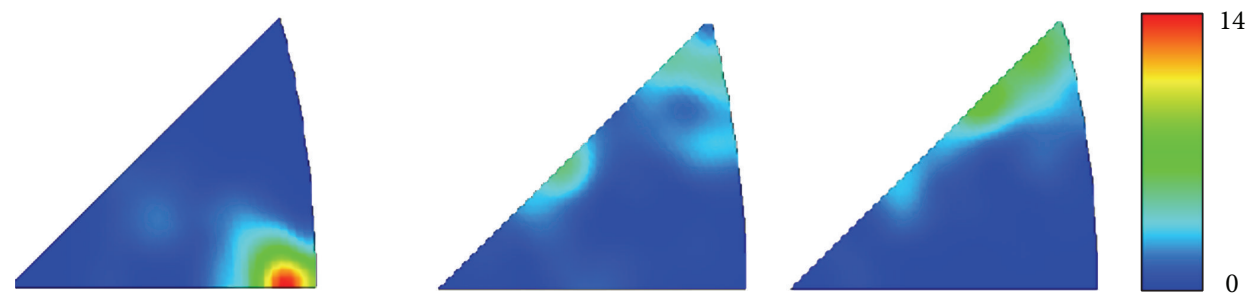

(b)
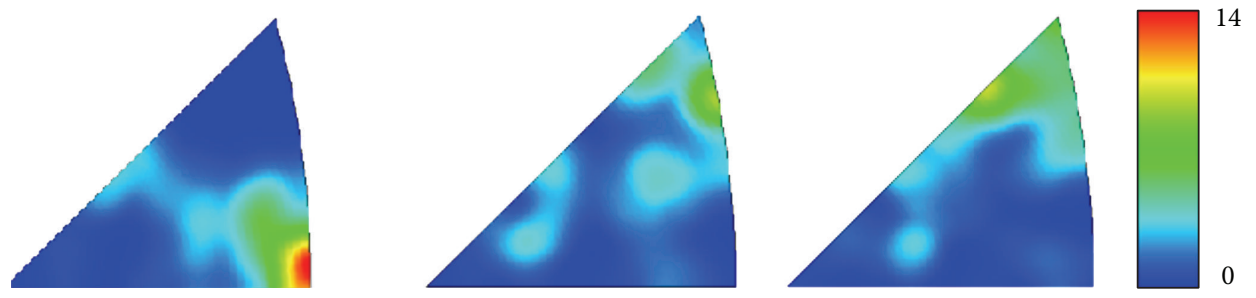

(c)
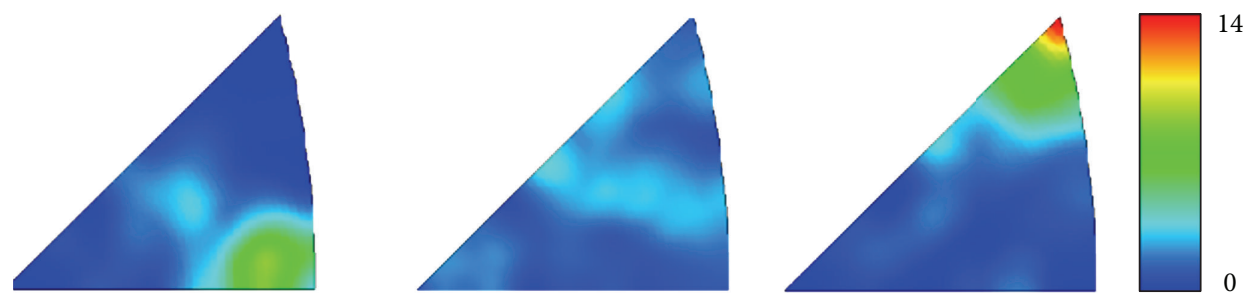

(d)
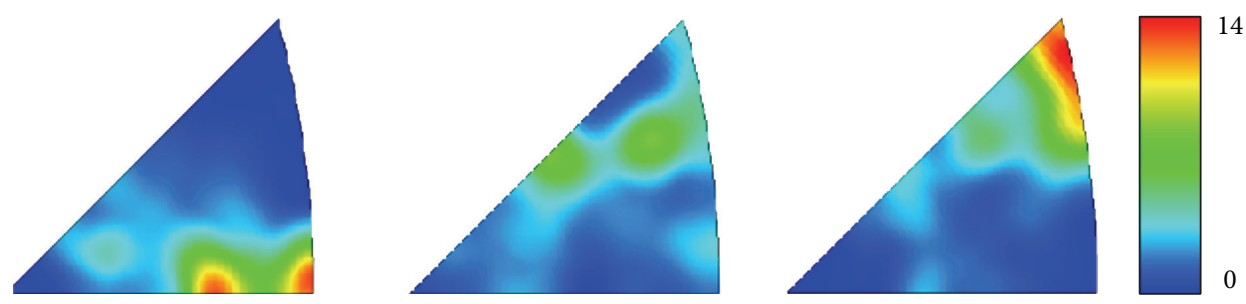

(e)
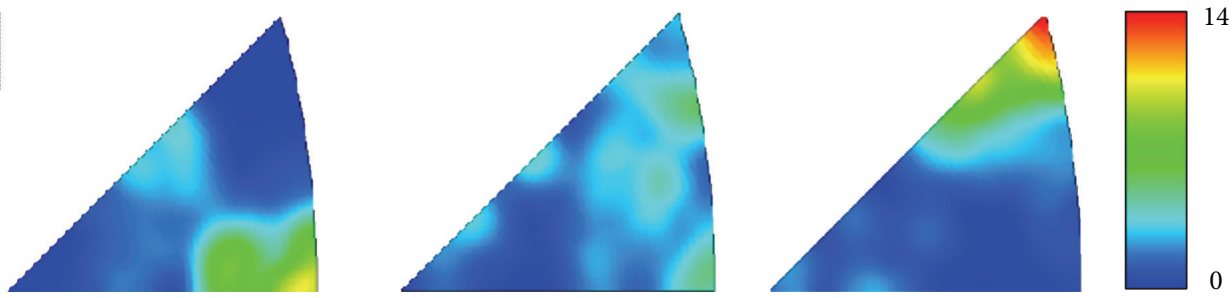

(f)

FIGURE 1: Inverse pole figures of steel after uniaxial tensile of $10 \%$ with varied deformation rate: (a) $0 \mathrm{~mm} / \mathrm{min}$ (before tensile); (b) $0.1 \mathrm{~mm} / \mathrm{min}$; (c) $1 \mathrm{~mm} / \mathrm{min}$; (d) $60 \mathrm{~mm} / \mathrm{min}$; (e) $120 \mathrm{~mm} / \mathrm{min}$; (f) $300 \mathrm{~mm} / \mathrm{min}$. 

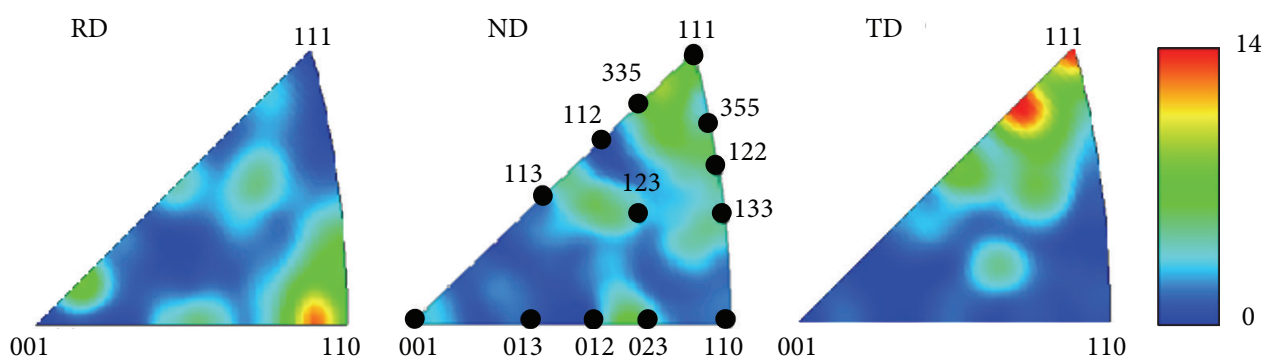

(a)
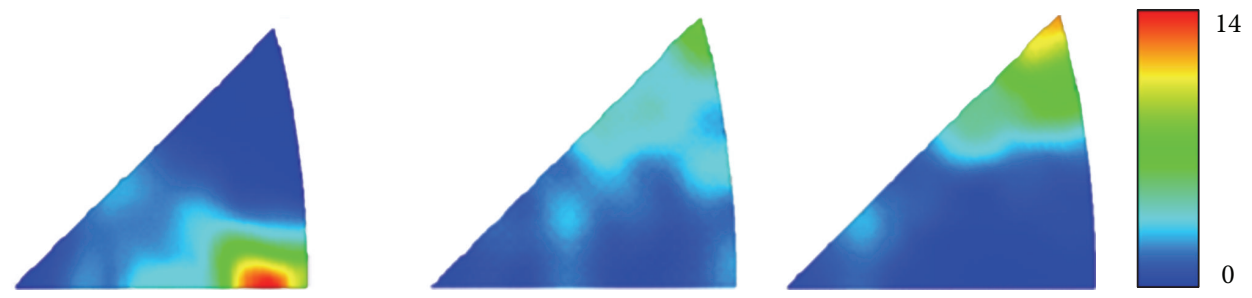

(b)
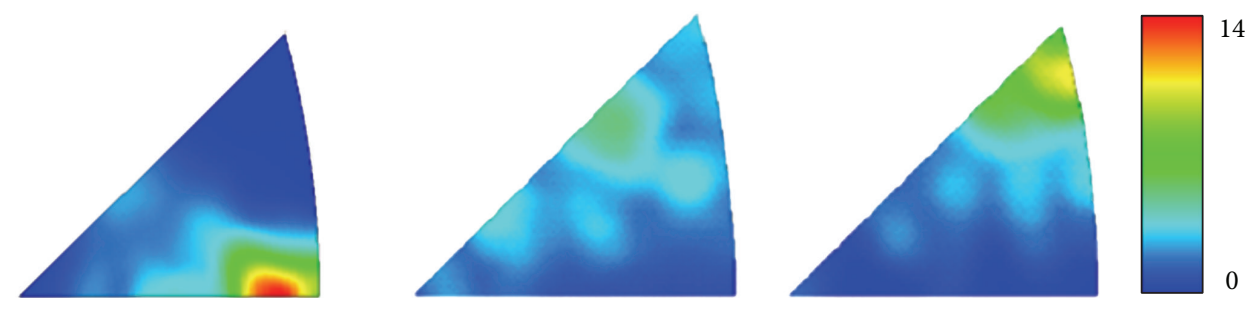

(c)
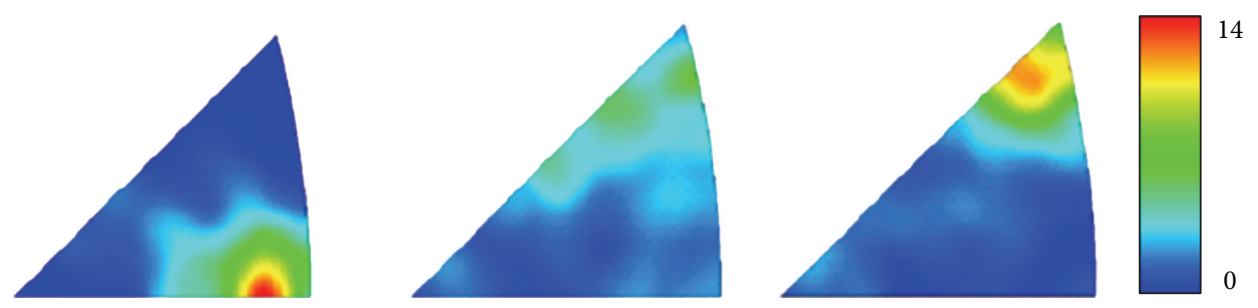

(d)
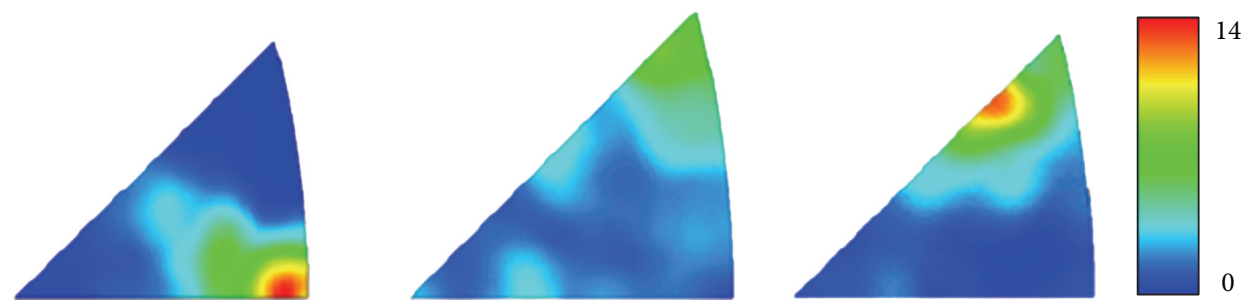

(e)
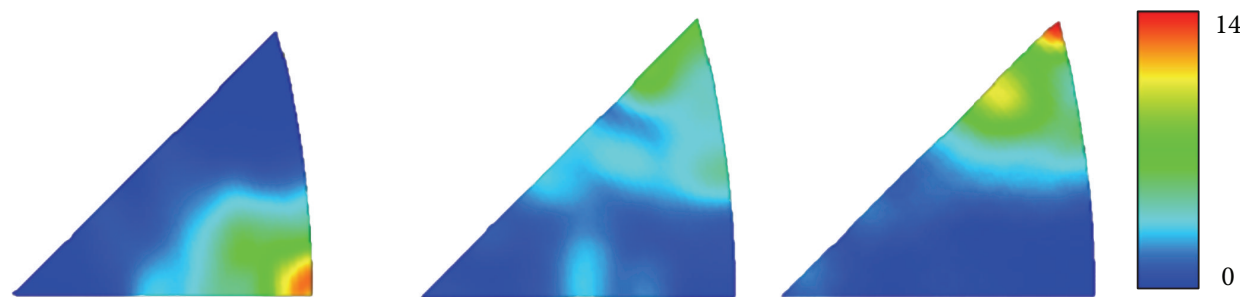

(f)

FIGURE 2: Inverse pole figures of steel after uniaxial tensile of $20 \%$ with varied deformation rate: (a) $0 \mathrm{~mm} / \mathrm{min}$ (before tensile); (b) $0.1 \mathrm{~mm} / \mathrm{min}$; (c) $1 \mathrm{~mm} / \mathrm{min}$; (d) $60 \mathrm{~mm} / \mathrm{min}$; (e) $120 \mathrm{~mm} / \mathrm{min}$; (f) $300 \mathrm{~mm} / \mathrm{min}$. 

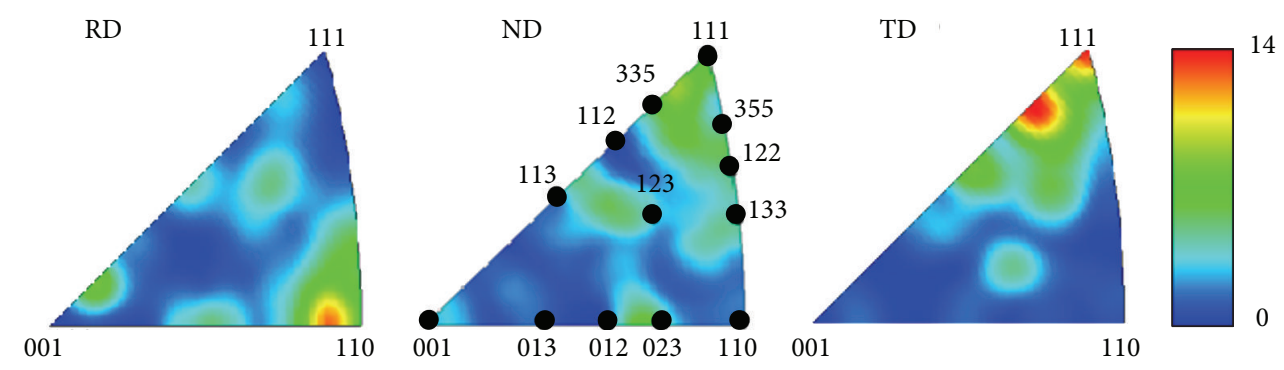

(a)
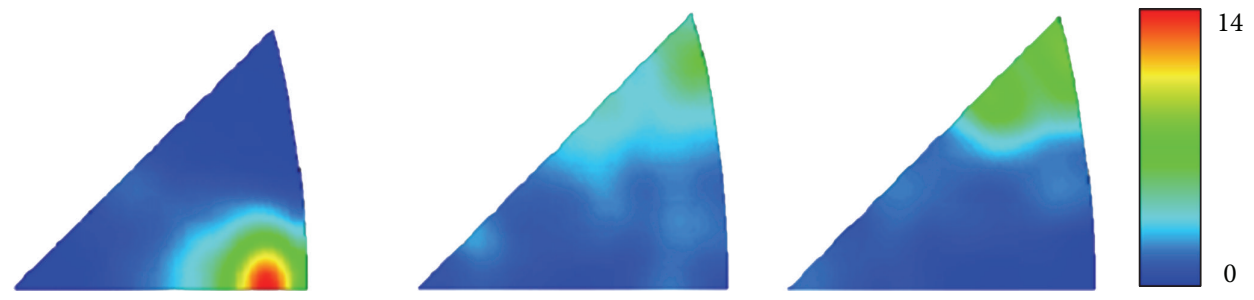

(b)
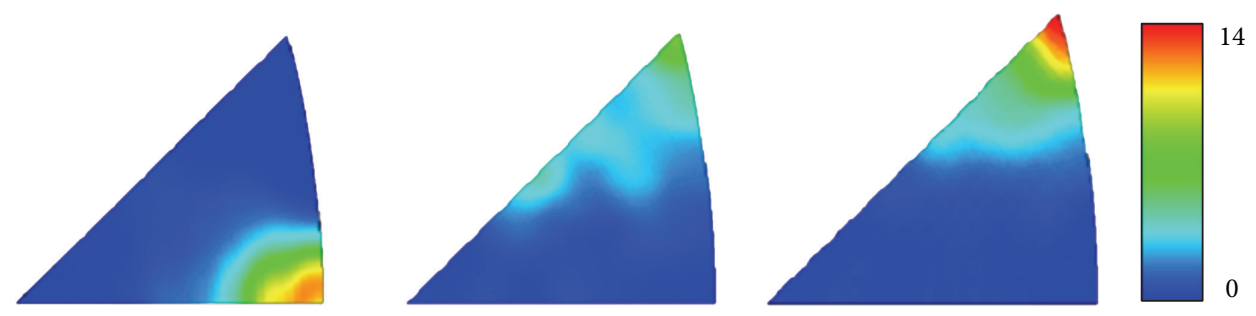

(c)
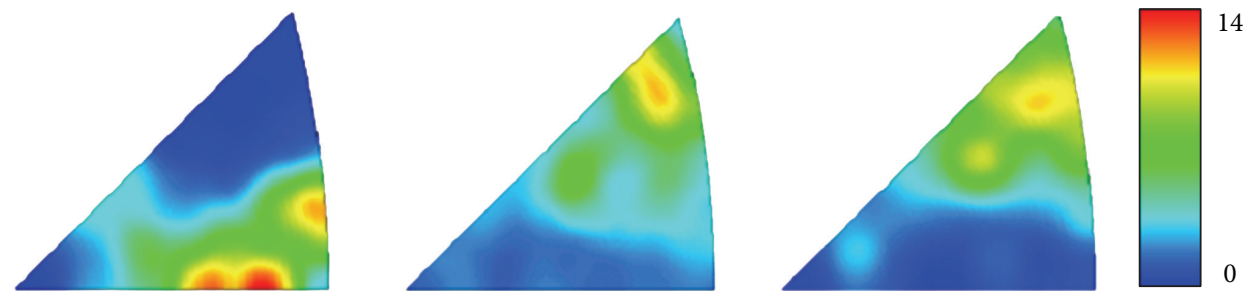

(d)
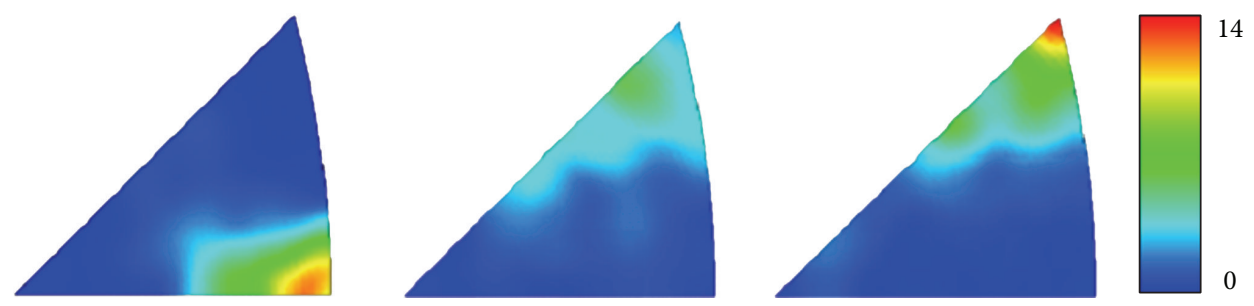

(e)
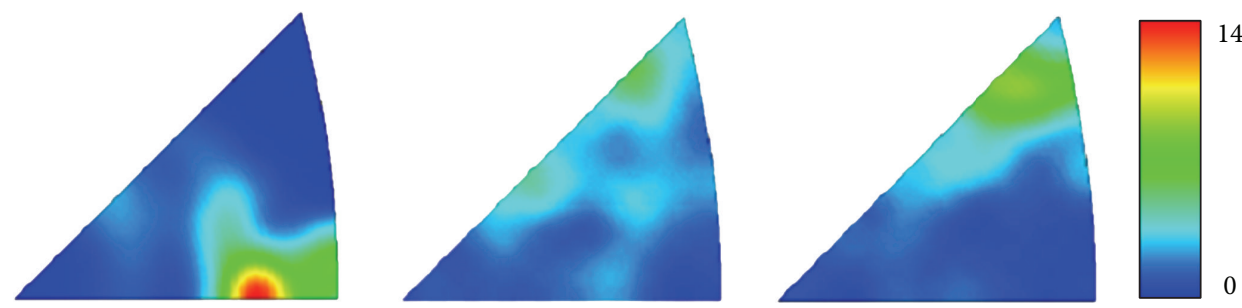

(f)

FIGURE 3: Inverse pole figures of steel after uniaxial tensile of $30 \%$ with varied deformation rate: (a) $0 \mathrm{~mm} / \mathrm{min}$ (before tensile); (b) $0.1 \mathrm{~mm} / \mathrm{min}$; (c) $1 \mathrm{~mm} / \mathrm{min}$; (d) $60 \mathrm{~mm} / \mathrm{min}$; (e) $120 \mathrm{~mm} / \mathrm{min}$; (f) $300 \mathrm{~mm} / \mathrm{min}$. 


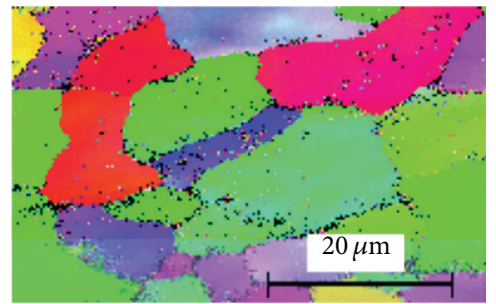

(a)

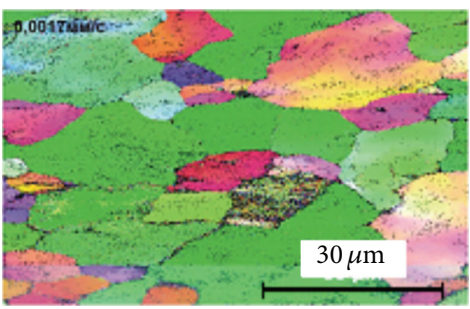

(b)

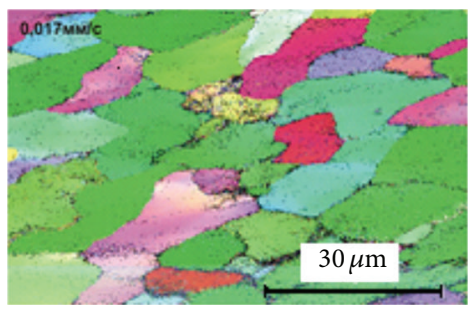

(e)

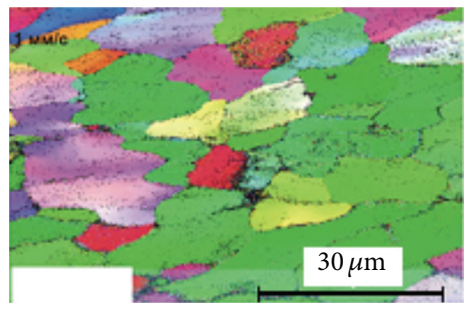

(h)

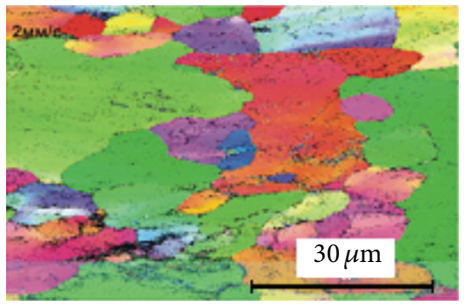

(k)

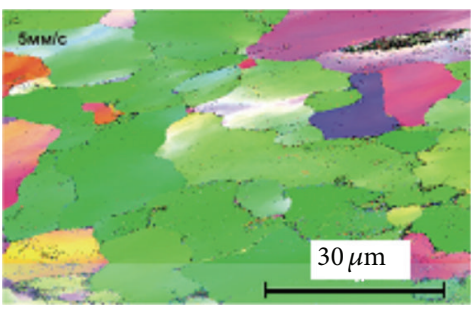

(n)
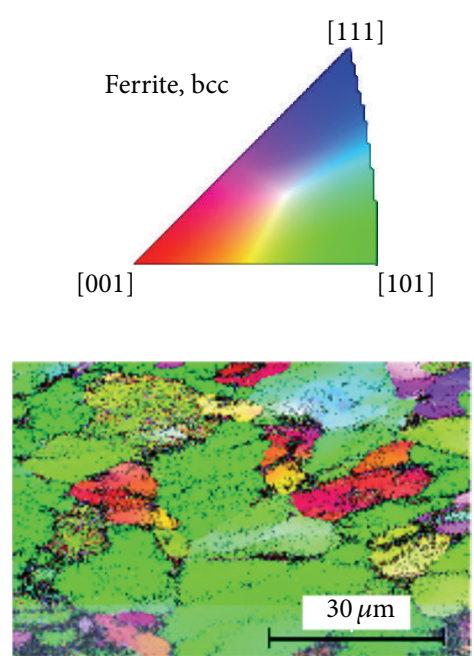

(c)

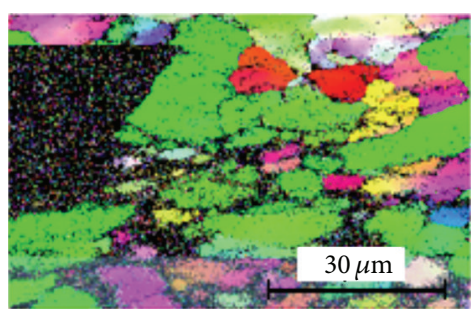

(f)

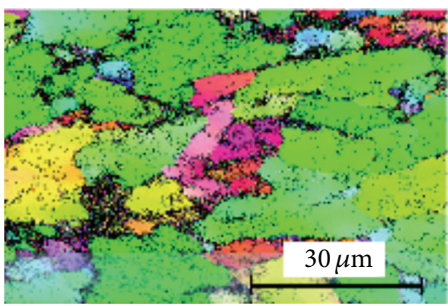

(i)

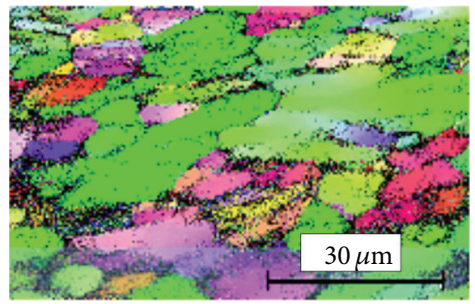

(1)

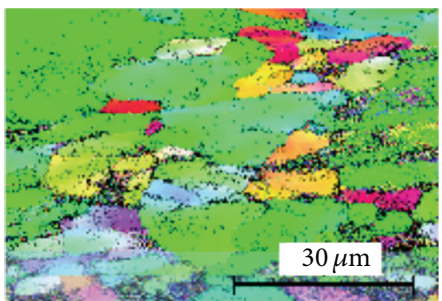

(o)

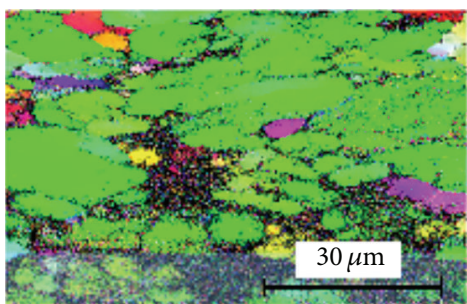

(d)

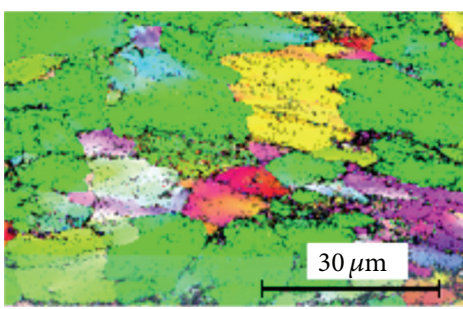

(g)

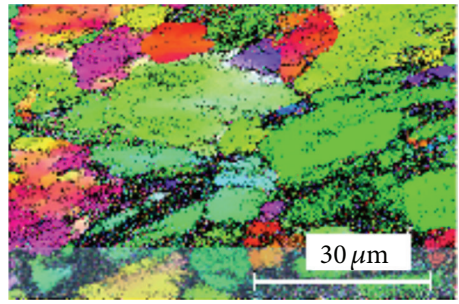

(j)

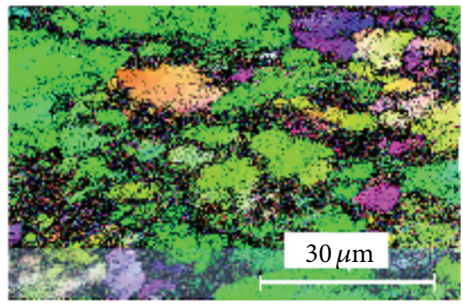

(m)

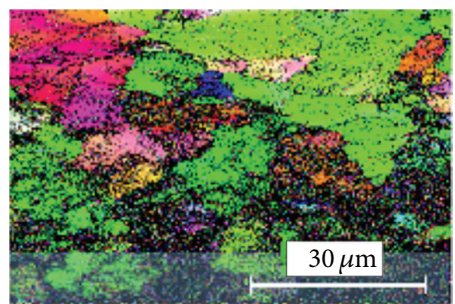

(p)

FIgURE 4: The microstructure of steel in the cross section perpendicular to the tensile direction in RD. Strain rate tensile: (a) $0 \mathrm{~mm} / \mathrm{min}$ (before tensile); (b-d) $0.1 \mathrm{~mm} / \mathrm{min}$; (e-g) $1 \mathrm{~mm} / \mathrm{min}$; (h-j) $60 \mathrm{~mm} / \mathrm{min}$; (k-m) $120 \mathrm{~mm} / \mathrm{min}$; $(\mathrm{n}-\mathrm{p}) 300 \mathrm{~mm} / \mathrm{min}$. Deformation degree: (b-n) $10 \%$; (c-o) $20 \%$; (d-p) $30 \%$. Gradation of intensity is as in Figures 1-3. 
which supplies the twinning dislocations during deformation via coplanar slip, is $(\overline{1} 01)[1 \overline{1} 1][7,9]$. As can be seen in Figure 4(j), the boundaries of the matrix ferrite are straight comparatively. But a series of notches is presented in some cases. These notches are due likely to either faults or to detwinning by slip, but their exact cause and nature have not been established [10].

Tensile strain in the RD at the same time is accompanied by the compression in the ND that leads to the formation of compression texture near $\{533\}$, as it showed on IPF ND (Figure 3(d)). Formation of this texture during the compression may be realized due to the primary and cross slip of dislocations on systems $\{110\}\langle 110\rangle$ [7].

The tensile strain by $10 \%$ at the strain rate of $120 \mathrm{~mm} / \mathrm{min}$ concentrates the pole density on the IPF (RD) mainly near the poles $\langle 320\rangle$ and $\langle 110\rangle$ (Figure 1(e)). The areas of increased pole density are concentrated near the $\langle 211\rangle$ and $\langle 321\rangle$ on the IPF (ND) also. An area of high pole density $(\sim 13)$ is formed near the $\langle 111\rangle$ direction with scattering to $\langle 221\rangle$ on the OPF (TD) in this case. Comparing the pole density distribution on IPF (Figure 1(e)) can conclude that in sheets the limited axial texture of between $\approx\{112\}\langle 110\rangle$ and $\{123\}\langle 210\rangle$ is formed with axis $\langle 111\rangle$ parallel to the TD when a tensile rate is $120 \mathrm{~mm} / \mathrm{min}$. Similar texture may be formed in the bcc metals during the tensile due to the activation of the primary slip system $\{110\}\langle 111\rangle$ with followed slip in coplanar planes [7] and due to sliding on the primary systems during the compression of sample in the ND [7] or in the process of tensile in the RD.

The tensile strain of $20 \%$ at the strain rate $120 \mathrm{~mm} / \mathrm{min}$ (Figure 2(e)) forms the texture similar to that which is formed by means of tensile strain of $10 \%$ at strain rate $1 \mathrm{~mm} / \mathrm{min}$ (Figure 1(c)).

The texture formed at the elongation of $30 \%$ at the rate of $120 \mathrm{~mm} / \mathrm{min}$ (Figure $3(\mathrm{e})$ ) is similar to the texture at the elongation rate of $20 \%$ with $0.1 \mathrm{~mm} / \mathrm{min}$ (Figure 2(b)).

The further increasing of the strain rate up to $300 \mathrm{~mm} / \mathrm{min}$ by means of tensile to $10 \%$ results in a certain weakening of the texture (Figure 1(f)). The maximal pole density $\langle 110\rangle$ on the IPF (RD) decreases to $\sim 12$. A maximum near pole of $\langle 210\rangle$ decreases to 10 . IPF (ND) is characterized by a wide scatter of increased pole density. There are peaks of $\sim 6$ near $\langle 332\rangle$ and $\langle 110\rangle$, as well as the maxima of $\sim 5$ near the poles $\langle 112\rangle,\langle 321\rangle$, and $\langle 135\rangle$. There is also scatter of pole density from the maximal value of 14 in the pole $\langle 111\rangle$ to the level of $\sim 10$ close to $\langle 533\rangle$ pole on the IPF (TD). This argues that grains rotate around TD during the tensile. Thus, the texture that is formed at a tensile rate of $300 \mathrm{~mm} / \mathrm{min}$ by $10 \%$ may be described as a set of orientations $\{011\}\langle 110\rangle$, $\{332\}\langle 110\rangle,\{321\}\langle 121\rangle,\{112\}\langle 110\rangle$, and $\{135\}\langle 211\rangle$. A similar trend with a tensile speed of $300 \mathrm{~mm} / \mathrm{min}$ by 20 and $30 \%$ (Figures $2(\mathrm{f})$ and $3(\mathrm{f})$ ) is observed.

Texture scattering in the wide range of orientations may testify to the realization of noncrystallographic mechanisms of plastic deformation by means of slipping of disordered intergrain boundaries due to difficulty of intragrain slip processes. The effect of texture scattering with increasing strain rate was observed in [6] after tensile tests of aluminum alloy.
Thus, the texture analysis demonstrates that increasing the rate of deformation by uniaxial tensile to the $120 \mathrm{~mm} / \mathrm{min}$ changes the initial texture. There are formed limited axial textures by activating crystallographic deformation mechanisms. At the same time there is observed certain regularity of influence of degree and strain rate on the texture formation. Particularly, the texture that formed during the tensile by $10 \%$ at a rate of $0.1 \mathrm{~mm} / \mathrm{min}$ (Figure $1(\mathrm{~b})$ ) is being formed again, but at an elongation of $20 \%$ at a rate of $60 \mathrm{~mm} / \mathrm{min}$ (Figure 2(d)). The texture, which is produced during the tensile strain by $30 \%$ at a strain rate of $120 \mathrm{~mm} / \mathrm{min}$ (Figure 3(e)), is similar to texture at an elongation by $20 \%$ at the strain rate $0.1 \mathrm{~mm} / \mathrm{min}$ (Figure 2(b)), as is described above. In other words, the small tensile strains at a low strain rate are more favorable to the formation of one or another texture.

The further increasing of strain rate activates the noncrystallographic mechanisms of plastic deformation associated with the intergranular slipping due to the difficulty of crystallographic slip processes.

The above described texture transformations naturally are associated with changes of the mechanical properties, which are presented in Table 1. The anisotropy of the yield strength is observed. Meaning of yield strength in TD $\left(\sigma_{0.2} \mathrm{TD}\right)$ exceeds its value in the $\mathrm{RD}\left(\sigma_{0.2} \mathrm{RD}\right)$. This behavior of the yield stress is caused by crystallographic texture of specimens.

The crystal axes $\langle 111\rangle$ and $\langle 110\rangle$ are orientated in the $\mathrm{TD}$ and the RD, accordingly (Figure 1). The crystals with the orientations of $\langle 111\rangle$ are more resistant to the strain than crystals with the orientations $\langle 110\rangle$ [11].

It is usually assumed that the greater effect of hardening fits to the higher strain rate $[1,2]$. In the first approximation, we can estimate the hardening using the hardening coefficient $k$, which is the ratio of metal yield strength after hardening to the yield point before hardening [11]. The hardening coefficient in $\mathrm{RD}\left(k_{\mathrm{RD}}\right)$ and in $\mathrm{TD}\left(k_{\mathrm{TD}}\right)$ does not change monotonically (see Table 1 ).

With increasing of deformation rate the values of $k$ increase and reach a maximum at the tensile rate of $120 \mathrm{~mm} / \mathrm{min}$. At this stage, the textures that are represented by means of limited axial orientations of the axes $\langle 110\rangle$ and $\langle 210\rangle$ parallel to the RD and limited axial texture with the axis $\langle 111\rangle$ parallel to the TD (Figure $1(\mathrm{e})$ ) are getting the most sharp.

The increasing strain rate up to $300 \mathrm{~mm} / \mathrm{min}$ decreases the hardening coefficient, as well as texture sharpness (Figure 1(f)).

The anisotropy of the tensile strength $\left(\sigma_{\mathrm{ts}}\right)$ is expressed considerably weaker than of yield strength $\left(\sigma_{0.2}\right)$ and shows the opposite character: tensile strength in the TD $\left(\sigma_{\mathrm{ts}} \mathrm{TD}\right)$ greater than tensile strength in the $\mathrm{RD}\left(\sigma_{\mathrm{ts}} \mathrm{RD}\right)$, likely, due to the structural texture, which is characterized by elongation of the grains predominantly in the RD (Figure 2).

The ability of a steel sheet to the deep drawing is expressed by the ratio of yield strength to the tensile strength $\left(\sigma_{0.2} / \sigma_{\mathrm{ts}}\right)$ (recommended $0.55-0.66[12,13])$. The values of $\sigma_{0.2} / \sigma_{\mathrm{ts}}$ in Table 1 are beyond the scope of that at deformation rates of 60 and $120 \mathrm{~mm} / \mathrm{min}$. It indicates that after these deformation rates the ability of studied sheets to the deep drawing deteriorates. 


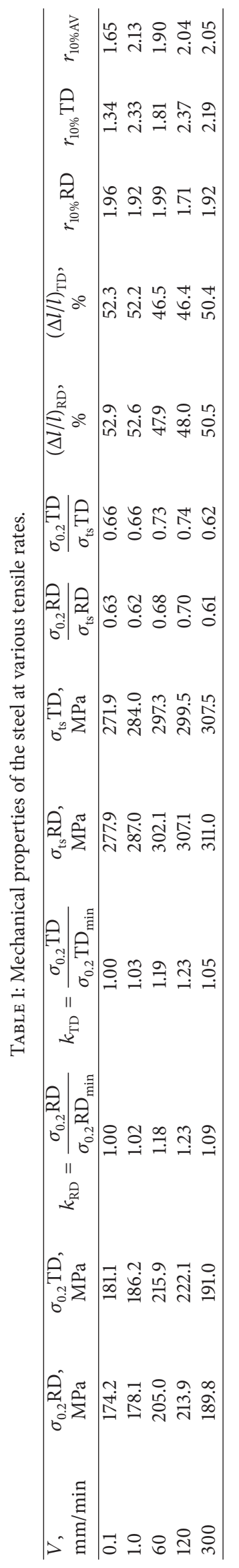


Elongation at break shows a trend opposite to the strength properties (see Table 1).

The coefficient of normal plastic anisotropy $r_{10 \%}$ has a value greater than 1.25 (see Table 1) that is recommended for deep drawing, when undesirable thinning of the sheet takes place [14].

At the same time, $r_{10 \%}$ changes in a complicated manner depending on the deformation rate (see Table 1). At a minimum tensile rate in the $\mathrm{RD}$ of $0.1 \mathrm{~mm} / \mathrm{min} r_{10 \%} \mathrm{RD}$ is greater than its value at tension in the TD $\left(r_{10 \%} \mathrm{TD}\right)$. There is a maximum of $r_{10 \%} \mathrm{RD}$ and minimum of $r_{10 \%} \mathrm{TD}$ if a tensile rate is equal to $60 \mathrm{~mm} / \mathrm{min}$. If the strain rate is equal to $120 \mathrm{~mm} / \mathrm{min} r_{10 \%} \mathrm{RD}$ and $r_{10 \%} \mathrm{TD}$ are of minimum and maximum values, respectively.

There is the significant linear correlation between the averaged arithmetic values of the coefficient of normal plastic anisotropy (in last column of Table 1) on the one hand and the averaged values of maximal pole density in the IPF (RD) and IPF (TD) on the other hand. The corresponding regression equation is of the form $y=0.41 x-3.23$, where a value of $y$ denotes the averaged arithmetic magnitude of the coefficient of normal plastic anisotropy $r_{10 \%}$ av. and $x$ denotes the arithmetic mean of the maximal pole density in the IPF (RD) and IPF (TD). The reliability coefficient of approximation $R^{2}$ is 0.81 .

\section{Conclusion}

The tests of uniaxial tensile by 10,20 , and $30 \%$ at strain rates of $0.1,1,60,120$, and $300 \mathrm{~mm} / \mathrm{min}$ in the rolling direction and the transverse direction of recrystallized cold-rolled specimens of low-carbon steel were carried out.

Texture of initial sheet is mainly represented via superposition of residues rolling texture $\{112\}\langle 110\rangle$ and recrystallization texture of mild steel that is close to the $\{111\}\langle 110\rangle$.

Tensile strain by 10 and $20 \%$ at the strain rates of $0.1 \mathrm{~mm} / \mathrm{min}$ and $60 \mathrm{~mm} / \mathrm{min}$ leads to the formation in a steel sheet of axial texture with the axis $\langle 110\rangle$ parallel to the rolling direction. Increase of the tensile strain at such conditions promotes the production of a planar texture of type $\{112\}\langle 111\rangle$.

The tensile strain by 10 and $20 \%$ at the strain rate of $1 \mathrm{~mm} / \mathrm{min}$ in a sheet leads to the formation of limited axial texture between $\approx\{335\}\langle 110\rangle$ and $\{355\}\langle 110\rangle$ with axis $\langle 110\rangle$ parallel to the rolling direction. Tensile strain by $30 \%$ at the strain rate of $1 \mathrm{~mm} / \mathrm{min}$ promotes to the formation of the planar texture.

Tensile strain by $10 \%$ at the strain rate of $60 \mathrm{~mm} / \mathrm{min}$ leads to formation in the steel sheet of limited axial texture between $\approx\{112\}\langle 110\rangle$ and $\{123\}\langle 320\rangle$ with the axis of $\langle 111\rangle$ being parallel to the transverse direction. Increasing of the degree strain during this helps to activate twinning.

If the tensile strain is $20 \%$ at strain rate $120 \mathrm{~mm} / \mathrm{min}$, a texture is formed similar to texture that was formed via tensile strain by $10 \%$ at the strain rate of $1 \mathrm{~mm} / \mathrm{min}$. Texture of tensile by $30 \%$ at rate of $120 \mathrm{~mm} / \mathrm{min}$ is similar to the texture of tensile by $20 \%$ at a rate of $0.1 \mathrm{~mm} / \mathrm{min}$.
It is observed that the small tensile strains at a low rate are more favorable to the formation of one or another texture.

The plastic deformation occurs as a result of activation of intragranular crystallographic slip on the systems $\{110\}\langle 111\rangle$ and by twinning on the conjugate planes $\{112\}$ at the strain rates up to $120 \mathrm{~mm} / \mathrm{min}$ inclusive.

Intragranular slip becomes difficult and grain boundary sliding is activated, when a strain rate is of $300 \mathrm{~mm} / \mathrm{min}$.

The increase of the strain rate from 0.1 to $120 \mathrm{~mm} / \mathrm{min}$ promotes to the increasing of hardening coefficient, yield stress, tensile strength, and their anisotropy. Percentage elongation at this shows the opposite trend.

If the strain rate is $300 \mathrm{~mm} / \mathrm{min}$, then is observed a blur of texture, reduction of coefficient hardening and anisotropy of echanical properties. At the same time tensile strength continues to increase and its value in the rolling direction is getting greater than its value in the transverse direction.

The significant linear correlation between the arithmetic mean of values coefficient of normal plastic anisotropy on the one hand and of the averaged maximal values of the pole density in the IPF (RD) and IPF (TD) on the other hand is found. The reliability coefficient of approximation has the value of 0.81 .

\section{Conflict of Interests}

The authors declare that there is no conflict of interests regarding the publication of this paper.

\section{References}

[1] "Plastic Deformation of Metals and Related Properties," http://www.newagepublishers.com/samplechapter/001425.pdf.

[2] "Types of Strain," in Manufacturing Processes for Engineering Materials, S. Kalpakjian, S. R. Schmid, and C. -W. Kok, Eds., Pearson Education, 5th edition, 2008, http://www3.nd.edu/ manufact/MPEM_pdf_files/Ch02.pdf.

[3] A. Bhattacharyya, D. Rittel, and G. Ravichandran, "Strain rate effect on the evolution of deformation texture for $\alpha$-Fe," Metallurgical and Materials Transactions A: Physical Metallurgy and Materials Science, vol. 37, no. 4, pp. 1137-1145, 2006.

[4] A. A. Bryukhanov, D. Fassman, and Z. A. Bryukhanova, "Effect of the tensile strain rate on the texture of sheets of St1.0312 steel," The Physics of Metals and Metallography, vol. 113, no. 7, pp. 721725, 2012.

[5] "Electron Back-Scatter Diffraction in the Scanning Electron Microscope: An Overview," http://materialsknowledge.org/ docs/GholiniaEBSDOverview.pdf.

[6] M. T. Pérez-Prado, G. González-Doncel, O. A. Ruano, and T. R. McNelley, "Texture analysis of the transition from slip to grain boundary sliding in a discontinuously recrystallized superplastic aluminum alloy," Acta Materialia, vol. 49, no. 12, pp. 2259-2268, 2001.

[7] Y. D. Vishnyakov, A. A. Babareko, S. A. Vladimirov, and I. V. Egiz, Theory of Formation of Textures in Metals and Alloys, Nauka, Moscow, 1979, (Russian).

[8] T. Senuma, H. Yada, R. Shimizu, and J. Harase, "Textures of low carbon and titanium bearing extra low carbon steel sheets hot rolled below their AR3 temperatures," Acta Metallurgica et Materialia, vol. 38, no. 12, pp. 2673-2681, 1990. 
[9] D. François, A. Pineau, and A. Zaoui, Mechanical Behavior of Materials, Volume 1: Micro- and Macroscopic Constitutive Behavior, 2012, http://books.google.com.ua/books?id=h8mtG Va9ZUUC\&printsec $=$ frontcover\&hl $=$ $\mathrm{ru} \# \mathrm{v}=$ onepage \&q\&f=false.

[10] L. E. Samuels, Light Microscopy Ob Carbon Steels, ASM International, 1999, http://books.google.ru/books?id=rsdbs92yGs4C \&printsec $=$ frontcover $\& \mathrm{hl}=\mathrm{ru} \# \mathrm{v}=$ onepage $\& \mathrm{q} \& \mathrm{f}=$ false .

[11] R. W. K. Honeycombe, Plastic Deformation of Metals, St. Martin's Press, New York, NY, USA, 1968.

[12] "Structural integrity assessment procedures for European industry," http://www.eurofitnet.org/sintap_BRITISH_STEEL _BS-25.pdf.

[13] A. C. Bannister, J. Ruiz Ocejo, and F. Gutierrez-Solana, "Implications of the yield stress/tensile stress ratio to the SINTAP failure assessment diagrams for homogeneous materials," Engineering Fracture Mechanics, vol. 67, no. 6, pp. 547-562, 2000.

[14] "Grundlagen der Blechumformung," http://www.bs-wiki.de/ mediawiki/index.php?title=Umformen\#Senkrechte_Anisotropie_r. 

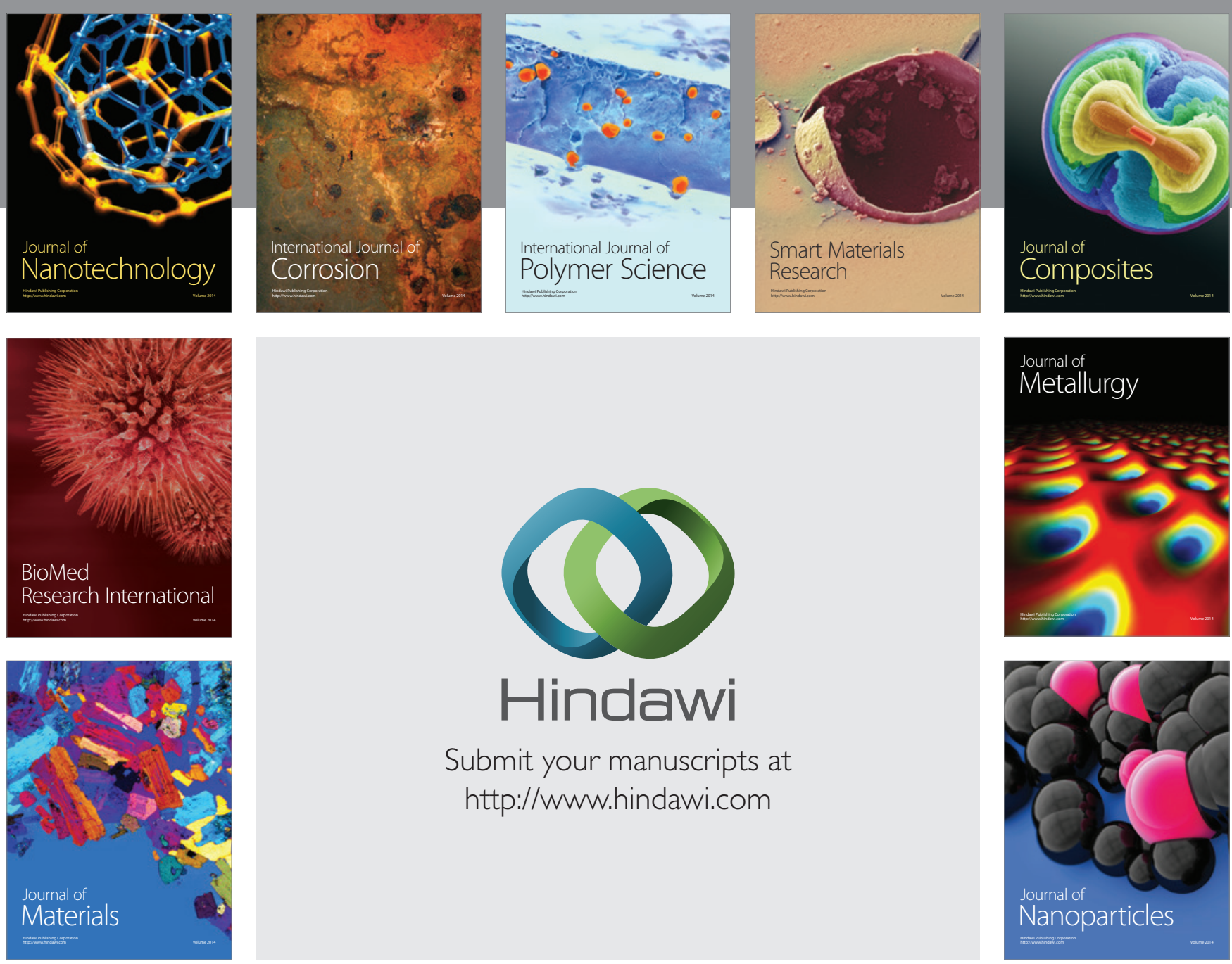

Submit your manuscripts at http://www.hindawi.com
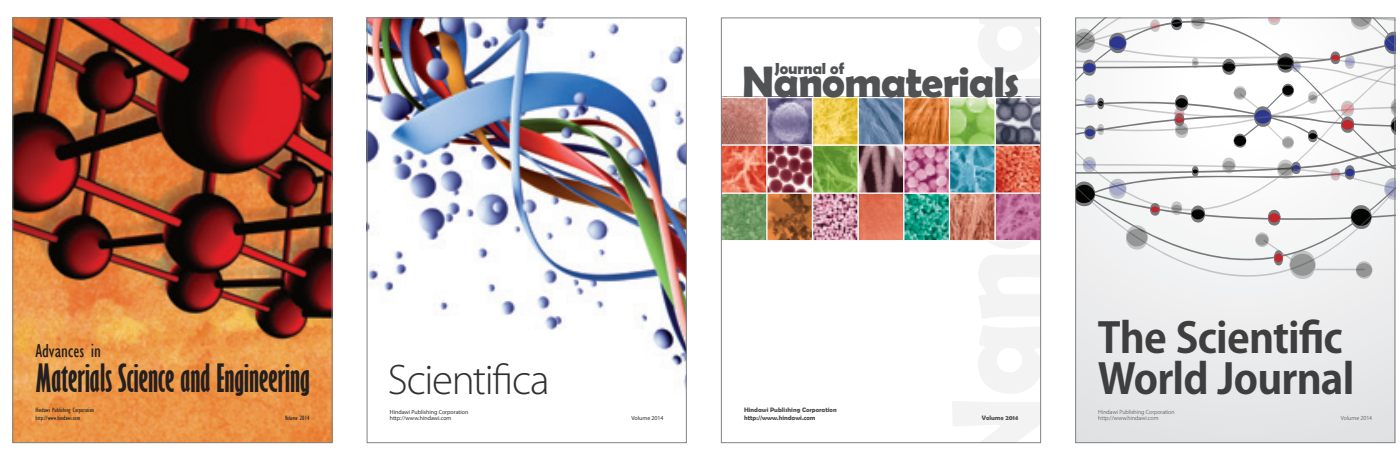

\section{The Scientific World Journal}
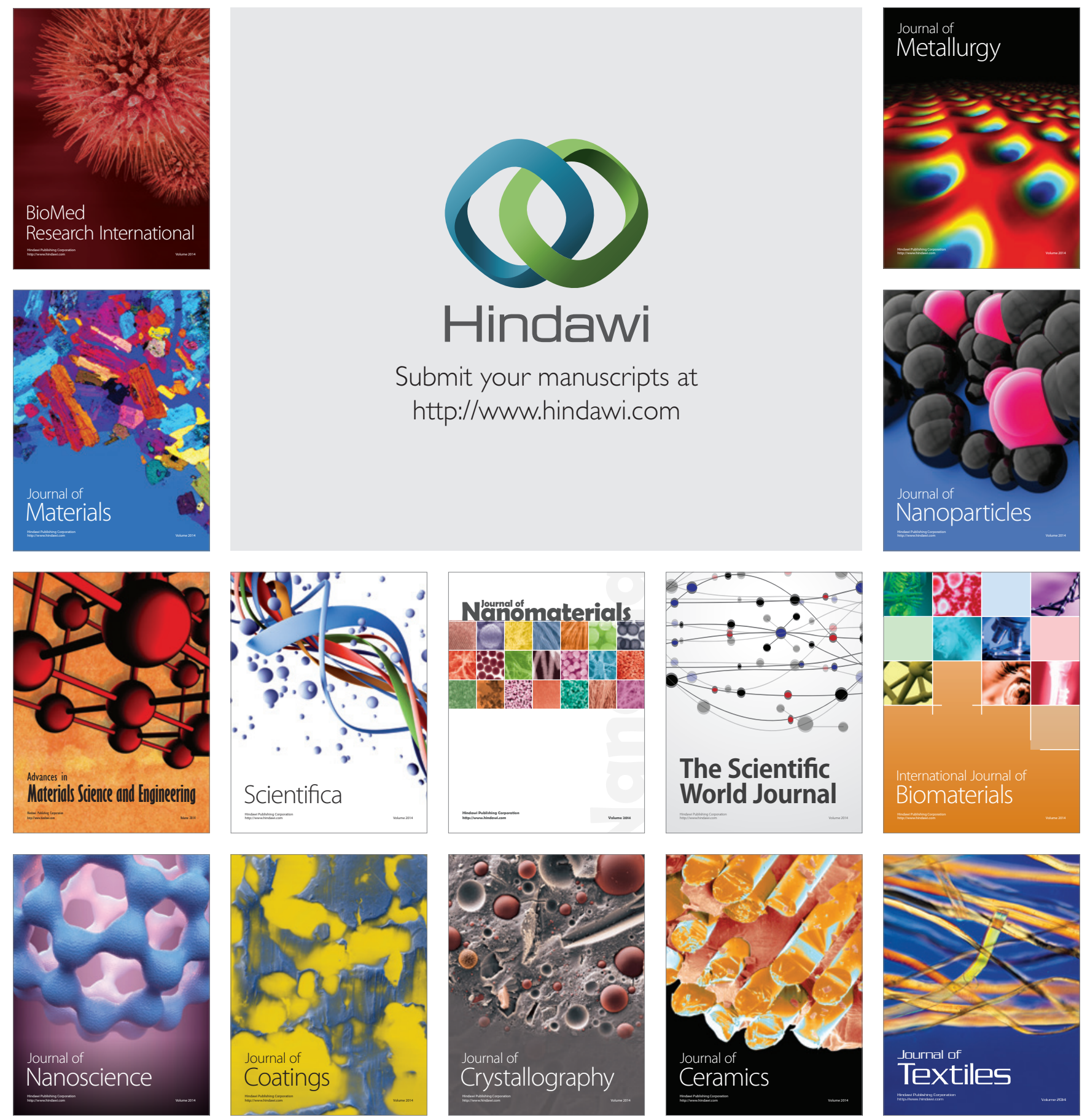